\title{
Combined Orthodontic And Surgical Correction Of An Adolescent Patient With Thin Palatal Cortex And Vertical Maxillary Excess
}

\author{
Hegde $M,{ }^{1}$ Hegde $C,{ }^{2}$ Parajuli $U,{ }^{3}$ Kamath $P,{ }^{4} M R D^{1}$
}

Department of orthodontics and dentofacial orthopedics

${ }^{1}$ DAPM R V Dental College and Hospital

Bangalore, India

\begin{abstract}
This paper describes the treatment of a male patient aged 14 years who presented with a skeletal class I, vertical maxillary excess, marked increase in overjet, thin palatal cortex and a gummy smile. Considering the severity of his malocclusion and its impact severity on his psychosocial well being, he was managed with a combined approach of Fixed Orthodontic therapy and Orthognathic surgery, even though his growth was not complete. Records of Pre treatment, Post treatment and three years in retention were analyzed and the functional and esthetic results were found to be fairly stable.
\end{abstract}

${ }^{2}$ Vydehi Dental College and Hospital, White field Bangalore, India

Department of Dentistry

${ }^{3}$ Gandaki Medical College

Pokhara, Nepal

${ }^{4}$ Manipal Teaching Hospital

Pokhara, Nepal

\section{KEY WORDS}

Orthognathic surgery in adolescents, vertical maxillary excess, thin palatal cortex

\section{Corresponding Author}

Manjunath Hegde

Department of orthodontics and dentofacial orthopedics

DAPM R V Dental College and Hospital

Bangalore ,India

Email: 21.hegde@gmail.com

Citation

Hegde M, Hegde C, Parajuli U, Kamath P, MR D. Combined Orthodontic And Surgical Correction Of An Adolescent Patient With Thin Palatal Cortex And Vertical Maxillary Excess. Kathmandu Univ Med J 2012;39(3):88-92.

\section{INTRODUCTION}

The goal of present day orthodontics is not only to bring about dental correction but also to achieve harmony between the craniofacial structures. This can be achieved with help of functional and orthopedic appliances in growing patients and surgical correction in patients whose growth is completed. However in some patients, certain functional, esthetic and psychosocial factors may necessitate early surgical intervention. ${ }^{1}$

Surgical management of growing patients with significant skeletal deformities remains controversial with regard to timing. The published literature has little to say on the appropriate timing of various maxillary surgical procedures in growing patients. ${ }^{1,2}$ Facial appearance is an important factor in determining social relationships and their peers often perceive significant dentofacial deformities as being less attractive. ${ }^{3}$ The psychosocial handicap imposed by an unaesthetic dental appearance may have a negative impact on the personality of children who are often subjected to ridicule in the form of teasing and name calling by 
their peers. ${ }^{4}$ Differences of behavior toward attractive and unattractive people have been well documented. ${ }^{5,6}$ Delaying surgery until growth is completed could be damaging to the patient's self-confidence. Thus early orthognathic surgery may hold important psychosocial implications for teenagers.

In this case report we present the management of a growing patient by a combined Orthodontic- Surgical procedure. Ideally surgical correction of skeletal discrepancies is carried out only after the completion of the growth, however in this patient even though growth completion had not taken place, combined orthodontic surgical procedure was carried out to relieve him from the psychological impairment caused by the malocclusion.

\section{CASE REPORT}

\section{Pretreatment Evaluation}

A male patient aged 14 years 5 months presented with a chief complaint of forwardly placed upper front teeth and inability to close his lips. He wanted improve his facial appearance at the earliest to eliminate pressure from his peers. He had no significant medical history and the temporomandibular joint function was normal. Clinical examination showed an Angle's class III subdivision, an overjet of $15 \mathrm{~mm}$ with impinging deep bite [fig 1a-c]. The patient also had incompetant lips, acute nasiolabial angle and a gummy smile [ fig 2a-c].

The cephalometric analysis showed a skeletal class I relation, severe vertical maxillary excess, thin palatal cortex and short upper lip. The PA view of the skull showed the lower right canine migrated to the lower border of the mandible on the left side and right canine impacted. The skeletal maturity status as seen on the radiograph of MP3 of the right hand showed that the patient was in the decelerating stage of growth [fig 3].

\section{Treatment Plan}

The patient was presented with the following treatment options

Two phase treatment with a orthopedic appliance initially to restrict the growth of maxilla and after the completion of growth surgical correction could be done. This approach was not satisfactory to the patient as it was not addressing his chief complaint and his immediate concern of esthetics which was causing him social embarrassment.

Orthodontic camouflage consisting of intrusion and retraction, was another treatment option but this was also limited considering the severity the malocclusion and the reduced thickness of the palatal cortex.

Combined orthodontic and surgical treatment was the third treatment option, which would relieve him from the psychological impairment caused during adolescence which was also the peak time of his personality development
Combined orthodontic and surgical treatment was decided for the patient considering the severity of the vertical maxillary excess, gumminess of the smile, and limitation of the orthodontic treatment due to thin palatal cortex. 0.022" Roth Pre Adjusted Edgewise appliance was chosen for the orthodontic correction. The lower impacted canines were recommended for extraction due to their unfavorable positions and lower first premolars were to be reshaped as canines. Maxillary Anterior Segmental Osteotomy with 8 $\mathrm{mm}$ of setback and $4 \mathrm{~mm}$ of vertical impaction was planned after extraction of upper first premolars.

\section{Treatment Progress}

Treatment was carried out in three phases:

\section{- $\quad$ Pre-surgical orthodontics \\ - $\quad$ Surgical treatment \\ - Post-surgical orthodontics}

Pre-surgical orthodontics: The orthodontic treatment was initiated with extraction of all four over-retained deciduous canines and upper and lower teeth were aligned. Extraction space of upper deciduous canines was utilized to improve the inclination of the upper anteriors. Upper canines and second premolars were uprighted and roots were made parallel to facilitate the surgical cuts. Prior to surgery, $0.019 "$ x $0.025^{\prime \prime}$ stainless steel wire were placed in the upper and lower arches.

Surgical treatment: Anterior maxillary osteotomy with

Table 1.Comparison of Pre,Post \& In retention Cephalometric values.

\begin{tabular}{|llll|}
\hline Cephalometric readings & Pre & Post & 3 years in retention \\
\hline SNA & $82^{\circ}$ & $83^{\circ}$ & $84^{\circ}$ \\
\hline SNB & $79^{\circ}$ & $81^{0}$ & $83^{\circ}$ \\
\hline ANB & $3^{\circ}$ & $2^{\circ}$ & $1^{0}$ \\
\hline WITS & $1 \mathrm{~mm}$ & $-5.0 \mathrm{~mm}$ & $-2 \mathrm{~mm}$ \\
\hline N-A-Pog & $-4^{0}$ & $-6^{0}$ & $-4^{0}$ \\
\hline SN GO GN & $38^{\circ}$ & $40^{\circ}$ & $40^{\circ}$ \\
\hline FMA & $32^{\circ}$ & $35^{\circ}$ & $36^{\circ}$ \\
\hline Yaxis & $71^{\circ}$ & $73^{\circ}$ & $75^{\circ}$ \\
\hline N-UI & $94 \mathrm{~mm}$ & $90 \mathrm{~mm}$ & $91 \mathrm{~mm}$ \\
\hline ANS - Gn & $84 \mathrm{~mm}$ & $78 \mathrm{~mm}$ & $82 \mathrm{~mm}$ \\
\hline
\end{tabular}

Table 2. Comparison of Pre,Post \& In retention Cephalometric values.

\begin{tabular}{|llll|}
\hline UI to SN & $125^{\circ}$ & $105^{\circ}$ & $107^{\circ}$ \\
\hline UI to NA & $44^{\circ}, 16 \mathrm{~mm}$ & $26^{\circ}, 9 \mathrm{~mm}$ & $28^{\circ}, 9 \mathrm{~mm}$ \\
\hline LI to MP & $92^{\circ}$ & $90^{\circ}$ & $88^{\circ}$ \\
\hline Stmi - UI & $9 \mathrm{~mm}$ & $2 \mathrm{~mm}$ & $2 \mathrm{~mm}$ \\
\hline Interincisal angle & $115^{\circ}$ & $140^{\circ}$ & $145^{\circ}$ \\
\hline Nasolabial angle & $60^{\circ}$ & $94^{\circ}$ & $103^{\circ}$ \\
\hline Sn - Stmi & $18 \mathrm{~mm}$ & $21 \mathrm{~mm}$ & $21 \mathrm{~mm}$ \\
\hline S line & $\mathrm{U}+4 \mathrm{~mm}$ & $\mathrm{U}-0 \mathrm{~mm}$ & $\mathrm{U}-2 \mathrm{~mm}$ \\
& $\mathrm{~L}+2 \mathrm{~mm}$ & $\mathrm{~L}+1 \mathrm{~mm}$ & $\mathrm{~L} 0 \mathrm{~mm}$ \\
\hline
\end{tabular}




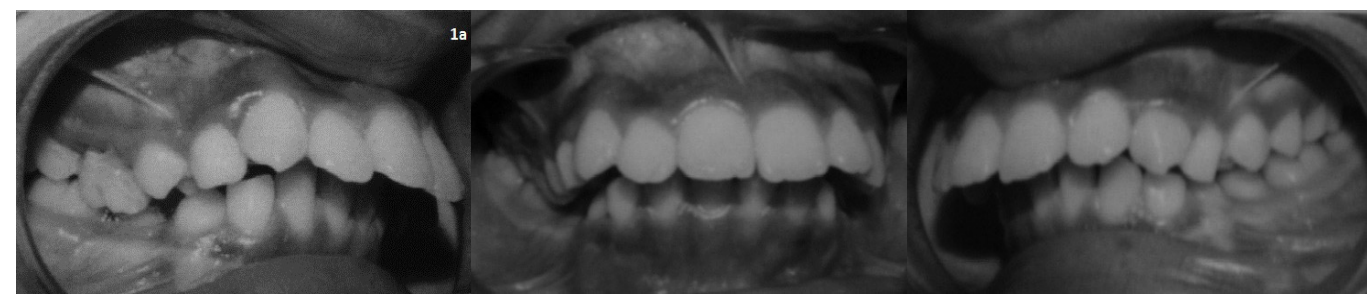

Figure 1a-c. Pretreatment intra oral photographs.

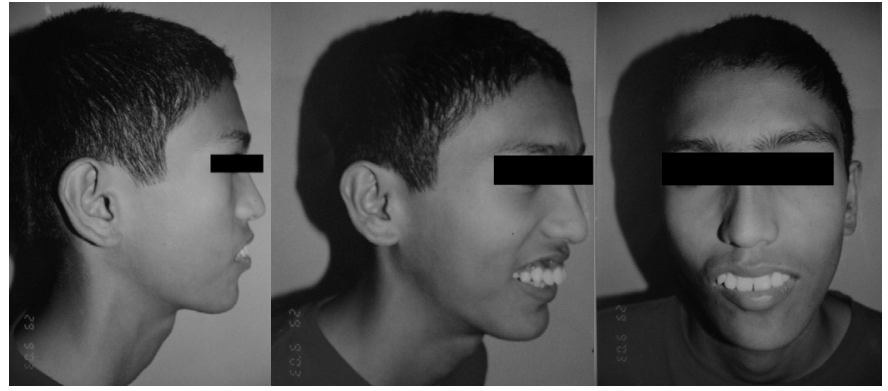

Figure 2a-c. Pretreatment extra oral photographs.

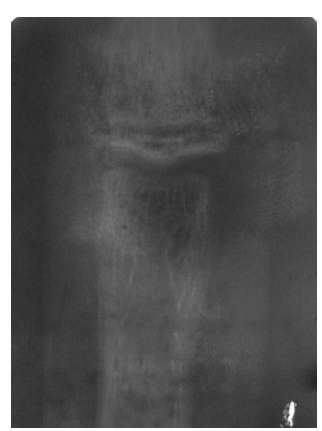

Figure 3. MP3 on a IOPA film.

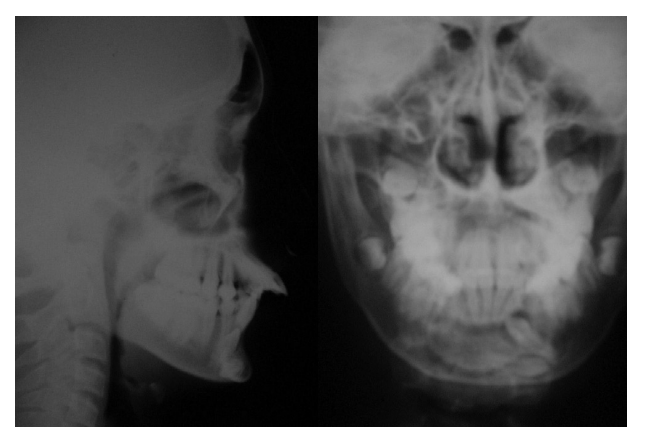

Figure 4. A. Pretreatment Lateral Cephalogram, B. Pretreatment Cephalogram.

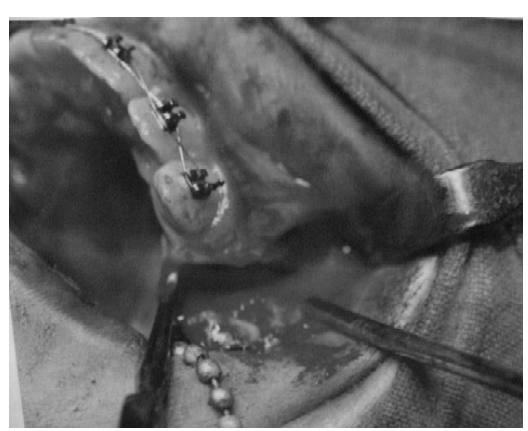

Figure 5. Anterior Segmental Osteotomy.

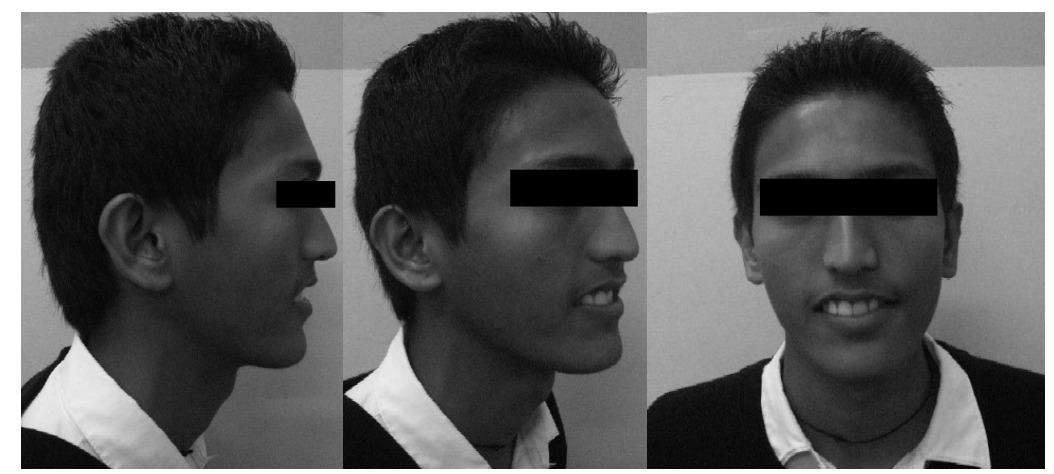

Figure 6. Posttreatment extra oral photographs.
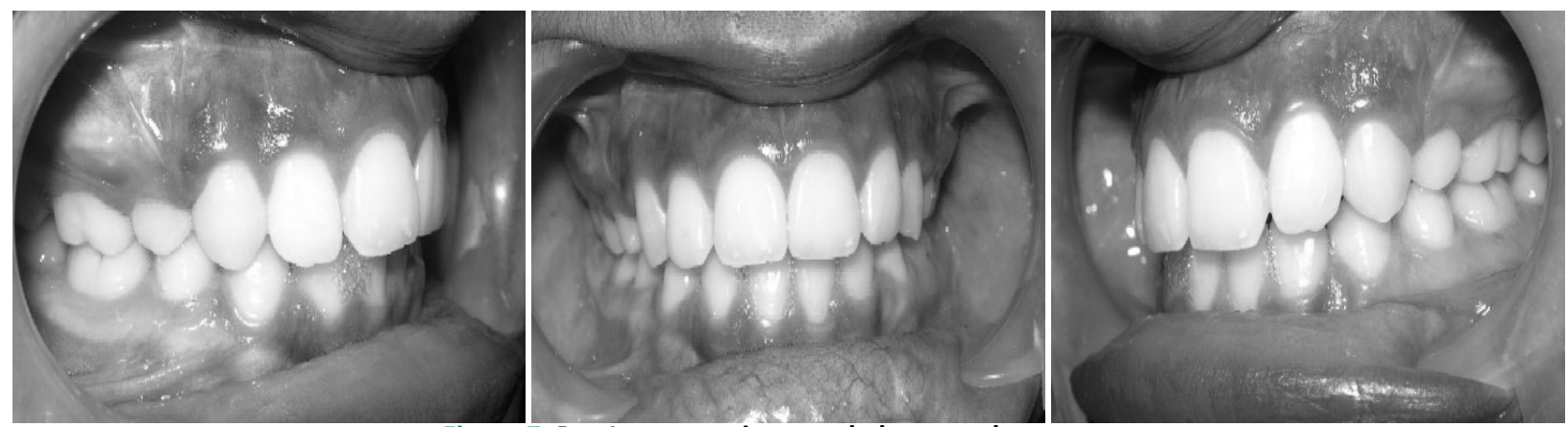

Figure 7. Posttreatment intra oral photographs. 


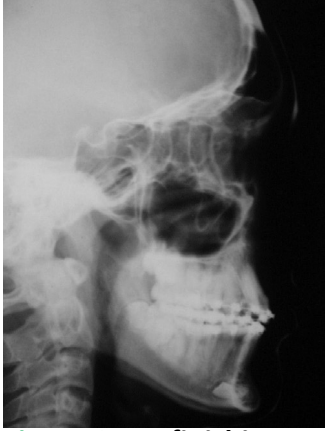

Figure 8. Prefinishing Lateral Cephalogram.

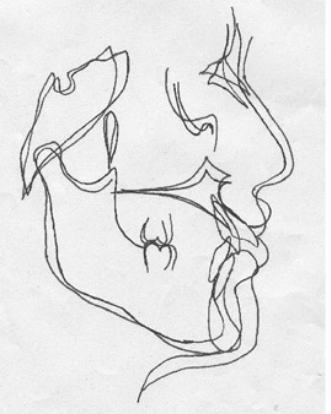

Figure 9. Overall Superimposition on $\mathrm{Ba}$ - Na plane at $\mathrm{CC}$ point of the pre-(Black) and prefinishing (red) cephalograms.

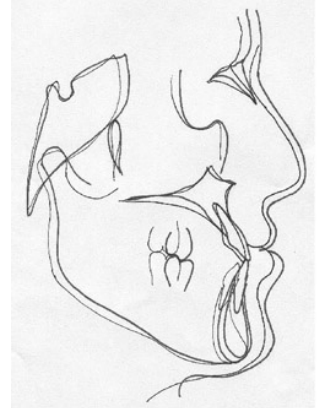

Figure 10. Overall Superimposition on $\mathrm{Ba}$ - Na plane at CC point of the post treatment(black) and 3yrs in retention(red) cephalograms.
Cupar's technique was carried after the extractions of upper first premolars [fig 5.] Impacted lower left canine was also extracted. Extraction of migrated right canine was planned for a later date. After the osteotomy 2 L-shaped plates with 4 holes was fixed.

Post-surgical: The remaining extraction space was closed by protraction of posteriors .The lower premolars were reshaped as canines and remaining posterior teeth brought forward to achieve a Class I molar and canine relationship. Post-surgical settling was done to achieve good interdigitation of upper and lower teeth. Fig 6 and 7 show the post treatment occlusion and the facial changes.

he total duration of treatment was two years and at the end of the treatment, an upper wrap around retainer with an intrusion splint was given. In the lower arch a fixed bonded lingual retainer from premolar to premolar was placed. The fig 9,10 show the pre treatment and pre finishing treatment overall superimposition on the BasionNasion plane.

\section{Long-term results}

The fig 6 and fig $7(a-c)$ show the intra and Extra oral photos three years in retention when the patient was 18 years. The Cephalometric changes are shown in table no 1 and 2 . The results were relatively stable even three years in retention.

\section{DISCUSSION}

Studies related to orthognathic surgery during in growing patients are few and the topic has been under a lot of debate. Williams et al studied factors of patients' motivation for undergoing orthognathic surgery in 326 patients. The major motivations for having treatment was to have straight teeth (80\%), prevent future dental problems (65\%), and improve self-confidence (68\%). ${ }^{7}$ Patients with a severe functional or psychosocial problems due to Skeletal maxillary excess can be treated at an early age provided sufficient space exists above the apices of the developing permanent teeth to place the osteotomies and fix the maxilla in the new position as quoted by Wolford, et al. ${ }^{2}$ effectively inhibits further anterior growth of the maxilla, while allowing vertical maxillary growth to continue at the same rate. ${ }^{8-10}$ However with the anterior segmental osteotomy the nasal septum remains attached to the hard palate so anterior-posterior maxillary growth may not be inhibited as in the case of Le fort $1 .{ }^{11}$ In this case a segmental technique was chosen for retraction of the protruded dentoalveolar segment and impaction, as the patient was a skeletal class I but had vertical maxillary excess with thin palatal cortices, which limited the orthodontic retraction.

Though the surgical correction could have been delayed till absolute completion of growth, the patients concern for esthetics and psychological implications of the malocclusion on the developing personality of the adolescent patient indicated for a relatively earlier surgical correction.

The patient had an internal motivation to undergo treatment because of socio-psychological impairment due to severity of malocclusion. Also the anatomic limitations for orthodontic treatment and severe proclination of the upper incisors making them prone to trauma necessitated early intervention rather than delaying treatment till growth was completed. The main goal of treatment with this growing patient was to boost the self-confidence of the patient during the prime period of personality development, and the same time restoring proper function, which was achieved successfully.

\section{CONCLUSION}

Orthognathic surgery may be a viable option in growing patients specially if the deformity is severe and is causing psychological impairment. However long term follow up will be necessary to ascertain the effects of surgery on the growth of the jaws and if relapse occurs due to continued growth then a second surgery may be necessary in certain cases. However the severity of malocclusion and the extent of functional, esthetic and psychological damage it has on the patient may justify early surgical intervention in growing patients. 


\section{REFERENCES}

1. Wolford L M, Spiro C K, Mehra P. Consideration for orthognathic surgery during growth, Part 2 : Maxillary Deformities. Am. J. Orthod. Dentofacial. Orthop 2001; 119: 95-101.

2. Wolford L M, Spiro C K, Mehra P. Consideration for orthognathic surgery during growth, Part 2 : Maxillary Deformities. Am.J. Orthod. Dentofacial. Orthop 2001;119: 102-5.

3. Mac Gregor F C. Transformation and identity .New York :Quadrangle :1974.

4. Cunningham SJ, Feinmann C, Ibbetson R. Disorders of appearance. In : Feinmann C ( Ed): The mouth ,The face and The mind. Oxford University Press $1999 ; 7$ :131- 56.

5. Shaw W C. Influence of children's dento facial appearance on social attractiveness. Am .J .Orthod 1981; 79: 399-415.

6. Shaw W C,Rees G, Dave M, Charles C R. Influence of dento facial appearance on social attractiveness. Am .J .Orthod 1985;87:21-6.
7. Williams A C,Shah H,Sandy JR,Travess HC. Patients'motivations for normal treatment and their experiences of orthodontic preparation for orthognathic surgery. J Orthod 2005;32(3):191-202.

8. Friehofer $H$ P Results of osteotomies of the facial skeleton in adolescence. J. Maxillofac. Surg 1977; 5:267-97.

9. Mogavero $\mathrm{F} \mathrm{J}$, Buschang $\mathrm{PH}$, Wolford L M. Orthognathic surgery effects on maxillary growth in patients with vertical maxillary excess. Am.J.Othod.Dentofac .Orthop1997;111:288-29.

10. Vig K W, Turvey T A. Surgical correction of vertical maxillary excess during adolescence. Int. J .Adult. Orthod Orthognath Surg 1989; $4: 119-28$.

11. Epker B N, Stella J P, Fish L C. Class I vertical maxillary excess. In: Dentofacial deformities: Integrative Orthodontic and Surgical correction.Vol II .2nd Edition.India : Reed Elsevieer India Pvt Ltd ;2007. pp 1015 - 1107. 